\title{
Ancol Jakarta Bay City as a sustainable destination park: assessing crowd based on tourism carrying capacity
}

\author{
R. A. Wahyuningputri \\ Trisakti Institute of Tourism, Jakarta, Indonesia
}

\begin{abstract}
The current sustainability of tourism development in Ancol Jakarta Bay City suggests that issues surrounding congestion, crowding and their relationship with the quality of the resort's carrying capacity will emerge as a significant problem in the future. Some causes of destruction occur in a tourism area if the maintenance process has not yet been finished because of sustainability development of the carrying capacity and therefore the related sector will be damaged. So, this research was created to identify factors that influence a visitor's perception of crowding in Ancol Bay City as a whole and each zone inside, based on indicators of the destination carrying capacity, and to solve problems related to crowd concerns so that they can be modified and prevented in a sustainable development process. While the theory of crowding in a destination carrying capacity was developed, a conceptual framework was also created, which is the operationalization of the theory, because it is a complex mental formulation of experiences, as crowding in a related destination could be damaging to the tourism carrying capacity. Factors that influence the sense of crowding can be classified into three groups: personal factors of each visitor, the characteristics of the encountered visitors and the characteristics related to the area visited. As a sustainable destination park, Ancol Dreamland must take some risks to maintain the existing destination park and also to make it better than before. This report examines issues of acceptability, crowding and visitor experiences at the destination park and suggests a framework for management of the visitor experience and the destination carrying capacity.

Keywords: destination parks, theme park, carrying capacity, crowd, perceived crowding, tourism.
\end{abstract}




\section{Introduction}

Nowadays, modern parks have become hybrids, thus during the 1990s in the USA, water parks all began to introduce thrill rides to compete with dry parks. Similarly, dry parks have added water parks adjacent to them. In the Middle East, Korea and South East Asia, there are many leisure parks that have been designed as indoor attractions similar to Europe and the USA. Large shopping complexes and malls have introduced leisure entertainment into their portfolio of activities.

As time goes by, themed entertainment attractions - known as theme parks are created into fantasy concepts, provoking atmosphere [1] as modified and implemented by the Disney Society and repeated around the world. According to well-known park designer Nate Naversen in Lee [2] a theme park is much more than an elegant place whose purpose is to entertain while using story-telling to move emotion. The Disney Corporation has a successful concept for theme parks and have sustainable destination parks around the world; visitors come to them for a short limited period of time and the park provides security and comfort [3] in a family oriented amusement complex with a range of subjects or historical periods, combining the continuity of costume and architecture with edutainment through rides and other attractions, catering and merchandising to provoke an experience called imagination or imagescapes [4].

A destination park must be well managed to maximize the number of visitors, but the effect in the long term is leading to crowding because of long-term growth, which will damage the destination area carrying capacity [5]. Appropriate prevention measures, including providing information about possible problem situations will help reduce negative crowding situations. [6]. One important aspect of tourism impact research that has not been examined is visitors' perceptions of their own impacts at a destination. Without knowing visitors' perceptions of their impacts at a destination, it is difficult to develop strategies to minimise negative impacts (destination damage) and to maximise positive benefits that visitors will have during their visit.

The focus of the research question is to know which factors are influencing unmanageable crowding in Ancol Dreamland based on carrying capacity differences in the studied sites. In detail, all of the objectives of the research will be focused on identifying factors that influence crowd conditions in the studied sites and Ancol Dreamland as a whole because they are related to the destination carrying capacity, in which it must be attended in these studied sites because of some differences of visitor's acceptability, satisfaction and tolerance values in related areas. This case is relevant to tourism destination studies and as a concept in tourism planning and sustainable development. The research explains and expands the understanding of crowding theory and contributes theories to develop the sustainability of tourism destination based on crowding issues. 


\section{Literature review}

\subsection{Crowding management}

Originally, crowding management was defined as the number of visitors that can be accommodated at a park without degradation of the biophysical quality of the area. It has evolved over time to include such meanings as how much change (defined in terms of human impact) from natural conditions is acceptable, but it still carries the implication of determining how many visitors are too many and when related environmental and social resources exceed the capacity of recreation area. Gifford in Endlicher [7] argued a psychological model; there are three categories of parameters influencing the emergence of crowding described as the physical setting, the social setting, and personal factors. Altman [8] in visitor use and Crowding Journal conceptualizes crowding as a situation in which individuals are unable to adequately regulate interpersonal contact.

The relevant studies on crowding name physical factors as contextually important but define crowding itself as a social phenomenon. Factors that influence the sense of crowding can be classified into three groups by Manning [9], they are "characteristics of the visitors themselves in their experiences" that are related to the duration and perception of each visitation. Also "characteristics of visitor encounter" that are related to the visitor's demographic factor and related conditions in the destination and "characteristics related to the area visited" as an intensity or purpose to visit a tourist attraction in a destination. Patmore [10] identified a continuum in recreational activities from those which "...exhibit a high degree of seasonality to those with a limited degree of variation in participation by season". Besides peak in day use, special events at an attraction are usually used as a tool for promoting a destination in each zone, and will absolutely influence crowd concern.

Visitor experience influences preferences of recreational activity because visitor perception of a destination park, or concept of destination image, is an integral and influential component of visitor's decision making process and travel behavior [11], and also, as a composite concept comprising interrelated cognitive and affective evaluations woven into an overall impression [12]. When their preference increases the amount of expenditure will also increase [13], because of the increased consumption of attraction facilities, services, and destination rides [14].

Many background differences can be manifested as age, gender, race, ethnicity, education, language preference, or a combination of these and other variables. Knowledge about visitor socio-demographic characteristics is essential for providing services in the theme park. In visitation patterns, activity choice is the concept to recreate in destination parks, and the reason to be involved in management decisions.

From an environment and physical perspective, the natural elements serve an important purpose, not only do they y offer resources, attrition, pollution, the uncontrolled use of which result in the kind of problems that cause conflicts between tourism and environmental protection related to these elements [15], but 
also the physical condition in an area will be influence visitor's perception, like a zone in a theme park. New games and rides will be more crowded than old ones. These conditions indicate a consistent relationship between the physical environment and perception, because visitor's perception can be an indicator of the quality of condition or special characteristic, environment and management.

\subsection{Crowding norm}

As mentioned earlier, crowding norms can be used to define a range of carrying capacity to measure use levels including: preference, desirability, pleasantness, ideal, favourableness, acceptability, satisfaction, okay and tolerance [9]. Absolute tolerance falls in the bottom of the range because it is based on visitor's perception of an area and preference is located at the high level. Normative standard theory and methods have attracted increasing attention in recreation research and management.

In particular, Manning [16] defined that norms may have special applications to setting standards of quality for recreation experiences. As applied to outdoor or indoor recreation, norms are generally defined as standards that individuals and groups use for evaluating behavior and social and environmental conditions, based on his theory of a social norm curve in the carrying capacity and crowding journal with VERP assessment for tourism destination [17].

As shown in figure $1([9,18])$ perceived crowding figures were applied to visitor based standards of quality for outdoor recreation based on their norms in a place visited. These applications relied heavily on the work of Manning [19] who said that personal norms can be aggregated to form social norms, or the degree to which norms are shared across groups. The norm curve highest point represents the optimal or preferred condition. A social norm defines the boundaries of acceptable encounter levels for an activity. The range of acceptable conditions represents the number of encounters that members of a group or an individual user find acceptable [9]. It includes all points on the norm curve above the

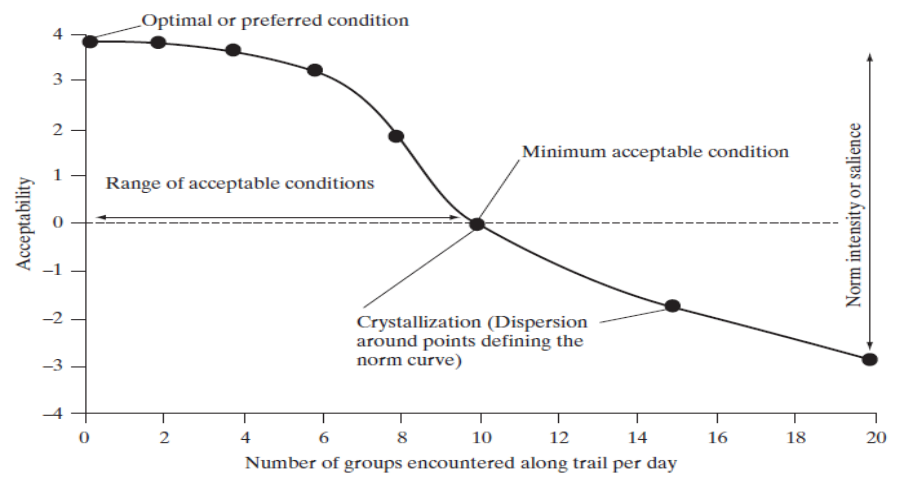

Figure 1: Hypothetical social norm of acceptability. 
zero point on the acceptability scale. The minimum acceptable condition is defined as the point at which the norm curve crosses the zero point on the acceptability scale. It is important to clarify why most visitors tend to express high levels of satisfaction, otherwise inaccurate information may be provided regarding visitor flow management. The crowding and encounter questions introduced in this study are actually behavioral indices of the general satisfaction question.

\subsection{Carrying capacity}

Middleston [20] defined Tourism Carrying Capacity (TCC) as the level of human activity an area can accommodate without the area deteriorating, the resident community being adversely affected or the quality of visitors experience declining. Also, the United Nations World Tourism Organization [21] proposed the following definition of carrying capacity - the maximum number of people that may visit a tourist destination at the same time, without causing destruction of the physical, economic, socio-cultural environment and an unacceptable decrease in the quality of visitors' satisfaction.

That is why Wagar [22] argued the hypothesis of carrying capacity cases where the relationship between nature and visitors can exceed certain ecological capacities, based on his 1964 theory about the first concept of carrying capacity in leisure sciences. This hypothesis was broadened by the integration of social and managerial aspects, comprising carrying capacity dimensions based on ecological, social, physical and managerial attributes. Manning [9] also states that "high visitor use can impact nature, can influence experiences of the other visitors" and it can be recorded using destination management measurements. Destination environmental carrying capacity, for instance, may be exceeded long before tourists perceive the place negatively [23] and supported Inskeep [24] who said that the tourist perception of when an exploitation of nature becomes unacceptable, may be reached before it is ecologically too late.

One early definition of carrying capacity by the Countryside Commission (1970) with the central precept of the long-term capacity of resources and human activity stated as embodied by the dual characteristics of protection and use the level of recreation use an area can sustain without an unacceptable degree of deterioration of the character and quality of the resource or recreation experience; there are physical, economic, ecological and social carrying capacity [25].

The Limits of Acceptable Change (LAC) system began with the fundamentals of the Recreation Opportunity Spectrum and initial principles of carrying capacity. Its design shifted the focus from a relationship between levels of use and impact, and Stankey and McCool [26] identified desirable conditions for visitor activity to occur in the first place.

Several workshop participants perceived that the only way to protect resources was to restrict use, and did not recognise the effectiveness of other actions. Limiting visitation may also unnecessarily restrict visitor freedom, and can be difficult and expensive to implement [27]. The reduction in use and other 
heavy-handed visitor restrictions are also perceived as a potential threat to generating tourist income, a high priority for many developing countries.

Overall, the basic theory in this case for a long term indicator of crowding can be regarded as the damage to the destination's carrying capacity that has been developed and accurately tested [5].

\subsection{Site management}

"The growing literature within the geographical studies of recreation in the 1960s and 1970s" Rodgers in Hall and Page [28]. Based on demand, site surveys have become the most documented methods of site management. Particularly, a specific site review often reveals impacts that occur off the development site or damage to downstream communities, fragile ecosystems and effect that are the result of many small actions, each of which appears too small to be important.

Glyptis in Hall and Page [28] highlights and states that "certain degrees of consistency in visitor use of a site, explaining the patterns as a function of the resource base, visitor use and behavioural factors". It may be possible to accommodate or reduce capacity through simple modifications as the geographer is well placed to examine fundamental aspects of recreation, to diagnose issues in site management, and to propose solutions.

The levels at which degradation and loss of key valued attributes of the environment begin to occur is clearly dependent upon the planning and management of a site. At 10 busloads of tourists per day, the Athabasca Falls site in Jasper National Park in the Canadian Rockies was showing severe degradation in the form of cliff erosion and trampling of plant species in this small and unique ecological zone, as well as endangering users who ventured too near the cliff edge to get a better view. Clearly, the natural thresholds had been exceeded and many key ecological and aesthetic values were in peril.

The design solution now permits a many fold increase in use, but with minimal impact on the valued natural attributes of the site. In effect, through a design improvement, the carrying capacity of the site has been increased significantly. It is used to maintain the valued attributes of the site by managing the impacts of use. Thus, the impact of a particular level of use or development, apart from its design, and the way in which human activity is now controlled or managed.

Based on the studied sites, factors influencing crowd conditions in Ancol Dreamland related to the carrying capacity of Ancol as a sustainable destination park were also related to tourism development as a green company. With the majority of concepts concerned with environment and physical conditions in this area because of some differences in related conditions [29]. Certainly, destination carrying capacity must be looked at in these studied sites because differences in visitor's acceptability in related area will influence the management action due to the crowd issues in these areas. That is why it is very important to identify factors influencing crowd condition in studied sites. Significantly, it is indicated that there are positive influences, and capacity differences in factors of perceived crowding, which will influence crowd conditions because capacity differences are apparent between beach areas with 
low capacity or high incidence of land use, and several theme parks. When factor differences are not shown clearly, the research will be taking average values and continuing with the structural modeling to represent Ancol Dreamland as a whole.

\section{Research design}

These phenomena about the destination park and the implementation in Ancol Jakarta City Bay is created in descriptive research [30]. By demonstrating the existence of social problems, competent descriptions can challenge accepted assumptions about the way things are and can provoke action, of course description can degenerate to mindless fact gathering or what Mills [31] called 'abstracted empiricism'. However, this is a function of inconsequential descriptions rather than an indictment of descriptive research itself. Perceived crowding is a psychological construct that exists in the minds of individuals and usually measured using closed-ended or open-ended questions following a nine point crowding scale for quantitative data and crowding scale interpretation [32]. It gives useful measurements to assess visitor perception of perceived crowding based on norms. Responses are given on a 9-point scale: A response of 1 or 2 indicates not at all crowded, 3-4 indicates slightly crowded, 5-7 indicates moderately crowded, and 8-9 indicates extremely crowded. With scale approaches, the visual research methods offer a potentially important research method that can be applied to measuring standards for parks and related areas. They offer several potential advantages to narrative or numerical descriptions of certain parks and outdoor recreation areas [33]. By using Homogeneity analysis, which shows the hypothesis is $\left(\mathrm{H}_{0}\right)$, there are significant indications of capacity differences in factors of perceived crowding that will influence crowd conditions because of capacity differences between a beach and other places with the theme park with low capacity or high risk of land use, rather than several theme parks because each $\mathrm{F}$ value $>0.005$.

\section{Research findings}

The questionnaires at Ancol Dreamland were distributed in seven places to 398 people. It was divided in to seven places within three zones at Ancol Dreamland recreational park. Respondent numbers totalled 355 amounting to an 89.2 percent questionnaire completion rate. Related to visitor experience, about 33.8 percent of respondents visit several times a year and 66.1 percent visit often because of their desires. This is influenced by their preferences of past experiences. Their experiences were influenced by images, about 84.2 percent very interested and 15.8 percent interested in visiting Ancol because of destination images they had seen.

In addition, about 33.3 percent of the respondents were very interested and 64.5 percent of the respondents were interested in visiting Ancol Dreamland because of their time spent doing activities, and 69.8 percent of the respondents were very interested because of attractions developed based on visitor needs in 
this destination park. When visitors spend their time in this recreational area, 69.8 percent of the respondents pay for special attractions and activities and 75.5 percent of the respondents consume other facilities like restaurants, gift shops and rentals and 76.1 percent of the respondents are very interested in visiting Ancol Dreamland because of special events like music concerts that are held in the area. It is supported by 47.4 percent of the respondents who like the building designs of the attractions or the performance area very much.

Besides, Ancol Dreamland has this number of visitors because the relationship between these visitors and the attractions is that 70.4 percent of the respondents felt very comfortable, and comfortable even if the area is very crowded and also about 76.1 percent of the respondents felt very comfortable when they saw and met many vehicles around the routes, especially in the full parking area, and 81.6 percent of the respondents still felt comfortable even when the number of arrivals increased causing crowd conditions.

Related to characteristics of visitors' encounters, their personality also influences their behavior. In actual conditions related to their behavior, 90 percent of the respondents are very bothered if other visitors cut across their track, 86 percent of the respondents are very bothered when other visitors speak loudly, 75 percent of the respondents are very disturbed by the generator machine and 59 percent of the respondents are very disturbed with music noise from other visitors or certain attractions. 92 percent of the respondents are very bothered with other visitors' sexual contact.

In addition, the high number of encounters also influences their behavior. 87 percent of the respondents in gateways, 66 percent of the respondents in sidewalk, 75 percent of the respondents in pathways, 65 percent of the respondents in ticketing, 90 percent of the respondents in attraction use or view point, 76 percent of the respondents in parking area and 84 percent of the respondents felt crowded with their encounter in these. Most visitors like to have nice experiences during their recreational time. That is why 67.3 percent of the respondents like to walk slowly and enjoy all facilities inside without having to physically touch and queue with other visitors and 82 percent of the respondents extremely dislike queuing for a new attraction or performance, but they have to endure it because the attractions are very interesting.

In relation to environmental conditions, 56.8 percent of the respondents said that the green spaces are available, 67.3 percent of the respondents absolutely agree with the conservation area and supported with 88 percent of the respondents felt comfortable with the cleanliness condition, 76 percent of the respondent are very comfortable with fresh air and 76 percent of the respondents are very comfortable with nice water condition. 86 percent of the respondents like to visit Ancol because of the attraction type and variety that suit their physical ability.

Not all visitors who visit these attractions will utilize these attractions and performances. Rest areas are also available in many places, 87.6 percent of the respondents said that there are many seats available at rest areas, 77 percent of the respondent said that there are many toilets available in certain attraction places or performances places, 64.4 percent of the respondents said that the area 
of the rooms at restaurants is very small for visitors movement except 87 percent of the respondents said that restaurants at the waterfront are large enough for them.

Their perception related to management policies; 87.2 percent of the respondents feel helped with very clear routes or signs around the destination park and 76 percent of the respondents like to see signs when they come to an area to visit an attraction or attend a performance, 86 percent of the respondents extremely agree with quick service and highly attentive staff.

The fact this destination park is totally different from other visitor perceptions of crowd related to the crowd itself. 67 percent of the respondents extremely accept the overload condition at certain pathways, 69.3 percent of the respondents totally accept the long queues, 56.3 percent of the respondents very much accept unfriendly and limited staff services, 67 percent of the respondents very much accept unsecure conditions, 58.3 percent of the respondent very much accepted the crowd conditions even though they lost appetite and 66.3 percent of the respondents very much accepted bad cleanliness in the area visited because of their tolerance of these conditions to get to their favourite attractions or performances.

Overall, the respondents are visitors in Ancol Dreamland that have some perception of perceived crowding based on standard norms. Visitors often continue and learn to be satisfied even when conditions become more crowded, often to the detriment of the resource. This phenomenon results in more bodies of water being managed for higher densities. The acceptance of crowded conditions results in fewer opportunities to manage for lower use levels and this statement is supported by the data that 77 percent of the respondents very much accepted crowd conditions, while 76.2 percent of the respondents are very satisfied, supported by 69.2 percent of the respondents who are very tolerant in crowd condition because of their own motivation.

Based on the questionnaires that were filled out by visitors above, indicators can be valued in these frequencies. The studied site was tested by homogenity test to assess the differences of carrying capacity of each location by using mean measures from each indicator in each factor divided into studied sites or related areas. Based on the analysis, the chart below will explain and answer the core problem of crowding in Ancol Dreamland.

Based on the square means above, these factors show the result that there are no differences among the factors influencing crowd even in different areas. In this case there is a clearly insignificant product difference of influence factors as is shown by statistics counted from: visitor experiences $(\mathrm{F}=0.43$, sig. $=1.000)$, characteristics of visitor encounters $(\mathrm{F}=0.245$, sig=0.961) and sites setting $(\mathrm{F}=248$, sig. $=0.960)$.

So, the hypothesis $\left(\mathrm{H}_{\mathrm{a}}\right)$ states that there are no significant indications of capacity differences in factors of perceived crowding, will influences crowd condition because capacity differences seems a beach with low capacity or high risk of land use rather than several theme parks because each $\mathrm{F}$ value $>0.005$. When factor differences are not shown clearly, the research will be taking average values and continuing to represent Ancol Dreamland as a whole [9]. It 


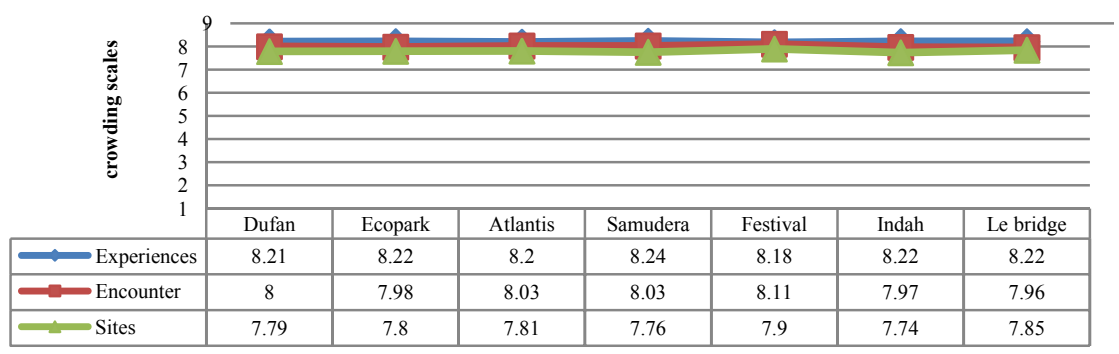

Figure 2: $\quad$ Crowd factor chart at studied sites.

can be attended specifically to do management action because it is high risk when all factors have a high number of crowd in all studied sites.

The factors show the high means that visitors accepted, all of actual use level or real condition in Ancol Dreamland. It means that the site layouts were acceptable and all of the visitors were satisfied in being there and enjoyed the crowd and created the tolerance value among them. They liked crowds and met many people there, even though they didn't know specifically about the long term effect of crowds damaging the carrying capacity in Ancol Dreamland [34].

As can be seen, in the table there is one row for each effect and one column for each of the quantities mentioned above. If a significant effect is found, one will normally be interested in comparing the means ${ }^{-} y i$ of each of the levels to identifying where the actual effect is. Each and every tourism destination and carrying capacity context, whether related to environment, physical and visitor encounter or another related function in these sites, is uniquely related with some theme park and the beach areas or same as visitor perception that factors in theme park the same as the beach areas.

The problem of crowd relates to Ancol as a sustainable destination park or related to tourism development as a green company, which "...the majority is talking about environment and physical condition in this area" [29]. Not only are destinations defined by a particular combination of environmental resources, natural or man-made, but the robustness or fragility of those resources, their significance or centrality to the tourism experience, and the scale, scope, character and stage of development of the tourism sector more generally represents parameters within which the tourism environment interface may be perceived and, consequently, appropriate policies for the management and development of tourism considered.

\section{Conclusion}

Overall, Thomas et al. [5] showed that long term crowding will be damaging to the destination carrying capacity. That is why management action needs to be attended to, to decrease the negative impact within destination parks and successfully manage carrying capacity. It needs management action and more 
studied experiences. A destination's environmental carrying capacity for instance may be exceeded long before visitors perceive the place negatively.

Time by time, more and more visitors are becoming loyal repeater visitors because the management always develops the program and many other things to keep the destination sustained. Assessing crowding based on preference dimension must be demonstrated and comprehensive knowledge of crowding responses as shown in the present work. Besides comparing crowding perceptions among the zones, it offered a comparative study of crowding among eastern, center and western beach zones in detail. Results demonstrated that visitor perception of several destinations are the same as at the other studied sites. Several differences are shown clearly, and environmental impact could be given in different time. In this setting, influences of management decision can be identified to show the efficiency of management action.

\section{References}

[1] Wanhill, Stephen. "Managing visitor attractions new direction”. Elsevier: Burlington. UK, pp.69, 2008.

[2] Daniel, G. Lee, Is your destination a theme park. A unique way to to view your community. Washington, DC. 2001. www.destinationmarketing.org /resource center/pdf

[3] McClung, G. W. Theme park selection: factors influencing attendance. In R. Ryan, and S. Page (Eds.). Tourism management. Towards the new millennium. Advances in tourism research series, Elsevier Science: Oxford, UK. pp.233-245, 2000.

[4] Zukin, S. "Lanscape and Power: From Detroit to Disneyworld. University of California Press: California, 1991.

[5] Thomas, R.N., Pigozzi, B.W., and Sambrook, R. A., Tourist Carrying Capacity Measures. The professional geographer. John Wiley and Sons, Inc : Hoboken, New Jersey, 2005.

[6] Heberlein, T.A. Reducing Hunter Perception of Crowding Through Information. Wildlife Society Bulletin. Springer-Verlag New York Inc, New York 1992.

[7] Wilfried, E. Human perception of urban environment and consequences for its design (Chapter 11). Perspectives in Urban Ecology: Ecosystems and Interactions Between Humans and nature in the metropolis of Berlin. Springer: London and New York, pp.309, 2011.

[8] Altman, I. The environment and social behavior . Monterey, CA: Brooks/Cole. Salt Lake City, USA: University of Utah, 1975.

[9] Manning, R. E. Studies in outdoor recreation, $2^{\text {nd }}$ edition. OR: Oregon State University Press, Corvallis, 1999.

[10] Patmore, J.A., Recreation and resources. Leisure pattern and leisure places. Oxford: Basil Blackwell. UK, pp.222-233, 1983.

[11] Gallarza, M.G., Saura, I.G and Gracia, H.C. Destination Image towards a conceptual framework. Annals of tourism research. pp.56-78, 2002. 
[12] MacKay, K.J. and Fesenmaier, D.R.. Pictorial Element of Destination in Image Formation. Annals of Tourism Research, 24 (3), pp.537-565, 1997.

[13] Huber F., Herrmann A., Morgan R.E. Gaining competitive advantage through customer value oriented management. Journal of Consumer Marketing, Vol. 18, No. 1, pp.41-53, 2001.

[14] Gutman J. A mean end model based on consumer categorization processes, Journal of Marketing. 1982.

[15] Young, G. Mapping Culture - A tool for sustaining cultures, the environment and tourism', National Cultural Commission, Papua New Guinea, 1995.

[16] Manning, R.E., Parks and Carrying Capacity, Commons without tragedy. Island Press: London, 2007.

[17] US Department of the Interior. The Visitor Experience and Resource Protection (VERP) Framework. A Handbook for Planners and Managers. CO: Denver Service, Denver, 1997.

[18] Shelby, B., and Heberlein, TA. Carrying capacity in recreation settings. OR: Oregon State University Press: Corvallis, 1986.

[19] Jackson, J. Structural characteristics of norms. Pages 301-309 in I. D. Steiner and M. F. Fishbein (eds.) Current studies of social psychology. Holt, Rinehart, Winston, New York, 1965.

[20] Middleton, V. and Hawkins, R. Sustainable Tourism: Marketing Perspective. Butterworth Heinemann: Oxford, UK, 1998.

[21] United Nations World Tourism Organization. Indicators of Sustainable Development for Tourism Destination. A guidebook WTO. Madrid, 2004.

[22] Wagar, J.A. The Carrying Capacity of Wild Lands for recreation. Forest Science Monograph. Society of American Foresters: Washington. DC, 1964.

[23] Walker, T.A. Tourism development and environmental limitations at Heron Island, Journal of environmental management. Great Barrier Reef, pp.119124, 1991.

[24] Inskeep, E. VNR Tourism and Commercial Recreation Series. Tourism Planning. An Integrated and Sustainable Development Approach. Van Nostrand Reinhold, New York, 1991.

[25] McKindsey, Christopher W at al. Review of recent capacity models for bivalve culture and recommendations for research and management. Burlington: Elsevier, 2006.

[26] McCool, S. F. and D.W. Lime. Tourism carrying capacity: tempting fantasy or useful reality. Journal of Sustainable Tourism. The University of Montana: Montana, 2001.

[27] Lindberg, K., McCool, S.F. et al. Rethinking carrying capacity. Annals of Tourism Research. The Ecotourism Society: North Bennington, 1998.

[28] Hall, M. and Page, S. The geography of tourism and recreation: environment, place and space. Third edition. New York: Taylor and Francis Group, pp.81-88, 2006. 
[29] Holden, Clark P. Release of Calcium from Inositol 1,4,5-Trisphosphate Receptor-Regulated Stores by HIV-1 Tat Regulates TNF- $\alpha$ Production in Human Macrophages. The Journal of Immunology, USA., pp. 164, 2000.

[30] Marsh, C. The survey method: the contribution of surveys to sociological explanation, London; Boston: Allen and Unwin, 1982.

[31] C.W. Mills The Sociological Imagination (extended review) Oxford University Press, UK. pp.71, 1959.

[32] Heberlein, Thomas A. and Jerry J. Vaske. "Crowding and visitor conflict on the Bois Brule River." Report WISC WRC 77-04. Madison, WI: University of Wisconsin Water Resources Center, 1977.

[33] Manning, R., and W. Freimund. Use of visual research methods to measure standards of quality for parks and outdoor recreation. Journal of Leisure Research 36:4, 552-579, 2004.

[34] Ancol, www.ancol.com 